\title{
COMPOSITION OF THE UPPER MANTLE: GEOPHYSICAL TESTS OF TWO PETROLOGICAL MODELS
}

\author{
Jay D. Bass and Don L. Anderson
}

Seismological Laboratory, California Institute of Technology, Pasadena, CA 91125

\begin{abstract}
The elastic properties of candidate mantle phases are used to test the viability of olivine-rich (pyrolitic) and $\mathrm{CaO}+\mathrm{Al}_{2} \mathrm{O}_{3}$-rich (eclogitic) assemblages for the mantle. High temperature adiabats for each phase of interest are constructed and compared to mantle seismic properties. Both pyrolitic and eclogitic assemblages satisfy the seismic properties between $\sim 200$ and $400 \mathrm{~km}$. Between 400 and $670 \mathrm{~km}$ depth an eclogitic assemblage yields a superior match to velocities and velocity gradients. The $400 \mathrm{~km}$ seismic discontinuity may represent a chemical boundary between pyrolite and picritic eclogite ("piclogite") or phase transformations in the olivine + orthopyroxene components of a piclogitic assemblage containing about $16 \%$ olivine. High velocity gradients in the transition zone may be explained by the transformation of Ca-rich cpx to majorite garnet. Seismic properties at the top of the lower mantle are consistent with pyrolite, piclogite or perovskite, implying that the $670 \mathrm{~km}$ discontinuity may be a chemical boundary.
\end{abstract}

Comparisons of laboratory elasticity data with seismic velocity profiles have been used in many studies to constrain the composition of the Earth's mantle. With few exceptions, it has been assumed a priori that the dominant minerals throughout the mantle are olivine (ol) and orthopyroxene (opx), coexisting with a small quantity of garnet (gt) and clinopyroxene (cpx). However, it remains to be demonstrated that ol-rich assemblages provide either a unique or the most satisfactory fit to the seismic data. Anderson (1976, 1979), Liu (1979), Lees et al. (1983), and Jeanloz and Thompson (1983) have discussed the difficulties of explaining the discontinuity at $670 \mathrm{~km}$ and the velocities in the transition region on the basis of phase relations in the ol and opx systems. A conclusion of the above studies is that the $670 \mathrm{~km}$ discontinuity may represent a chemical boundary. Differences in the Fe and/or Si (opx) content of the upper and lower mantle have been suggested, and Anderson (1979) proposed that the mantle between $220-670 \mathrm{~km}$ depth is dominated by gt + cpx (eclogite) rather than ol + opx. It is clearly desirable to test the viability of the gt-cpx hypothesis by direct comparison of the high pressure-high temperature velocities for such an assemblage with mantle velocity and density profiles. Although the stability fields and elastic properties of $\mathrm{CaO}$ and $\mathrm{Al}_{2} \mathrm{O}_{3}$-rich high-pressure phases are less well constrained than those of $\mathrm{ol}$ and opx, sufficient information exists for silicates and analog compounds to examine the plausibility of an eclogitic region. In this paper we calculate the compressional $\left(\mathrm{V}_{\mathrm{p}}\right)$ and shear $\left(\mathrm{V}_{\mathrm{s}}\right)$ velocities, and density $(\rho)$ of olivine, pyroxenes, garnets, and their polymorphs, at elevated temperatures and pressures. The properties of assemblages dominated by gt $+\mathrm{cpx}$ or ol $+\mathrm{opx}$ are then compared to observed mantle velocities and densities.

Copyright 1984 by the American Geophysical Union.

Paper number $4 \mathrm{~L} 0072$.

0094-827.6/84/004I-0072\$03.00

\section{Data Base}

Although elasticity data for silicates and oxides has been steadily accumulating, a number of important phases remain uncharacterized. We have therefore relied on systematics to estimate the properties of some high-pressure phases. Data on analog compounds for all pertinent crystal structures are available and they yield consistent elasticity patterns. Bulk modulus $(\mathrm{K})$ and rigidity $(\mu)$ are estimated from mean atomic weight or molar volume systematics and elastic constants of analog compounds. A complete discussion of our data base including $\mathrm{T}$ - and P-derivatives will be presented elsewhere (Bass and Anderson, in preparation).

The elastic and thermal properties and densities of ol, opx, gt, majorite (mj), (Mg,Fe)O, perovskite (pv), corundum and stishovite have been summarized previously $(O$. L. Anderson, et. al., 1968; Jeanloz and Thompson, 1983; and references therein). Elasticity data are also available for jadeite (e.g., Hughes and Nishitake, 1963), $\beta$ and $\gamma$ spinels (Weidner et al., 1984; Sawamoto et al., 1984) and diopside (Levien et al., 1979). For some phases only static compression results are available (e.g. $\mathrm{mj}, \mathrm{MgSiO}_{3}-\mathrm{pv}$ ) and in these cases measured values of $K$ were used with velocity systematics to define $\mu$ for a given compound. In the absence of other constraints, both $K$ and $\mu$ were estimated by velocity systematics. We note that perovskite-structure compounds exhibit well defined elasticity trends (Liebermann et al., 1977). For garnet-structures K ( 170 GPa) and $V_{p} / V_{s}(\sim 1.79)$ are virtually independent of composition and this has been assumed to apply to majorite $(K=220$ $\mathrm{GPa}$ ). Jadeite (jd), diopside (di), and opx, form majoritegarnet type solid solutions (Ringwood and Major, 1966, 1971). Molar volumes of the (hypothetical) majorite endmembers are estimated to be 101.0 (jd) and $122.6 \mathrm{cc} / \mathrm{mole}$ (di) by assuming ideal mixing in solid solution. The postmajorite phase of $\mathrm{jd}$-di solutions is thought to have a perovskite structure with end-member volumes of 32.1 (Ca$\mathrm{SiO}_{3}$, Ringwood and Major, 1971) and $24.9 \mathrm{cc} / \mathrm{mole}$ ( $\mathrm{NaAlSi}_{2} \mathrm{O}_{6}$, Reid and Ringwood, 1975).

\section{Results and Discussion}

In Figure 1 we show $V_{p}, V_{s}$ and $\rho$ for the low and high pressure phases of each component in our model mineral assemblages. The $1400^{\circ} \mathrm{C}$ adiabats were constructed using third-order Eularian finite strain theory (Sammis et al., 1970). All Fe-Mg silicates contain $10 \% \mathrm{Fe}^{2+}$ component, except garnet ( $\sim 20 \%$ almandite). Also shown are Earth model PREM (Dziewonski and Anderson, 1981) and other recent profiles (Grand and Helmberger, 1984; Walck 1984; Given and Helmberger, 1980). A common feature is the high velocity gradient between 400 and about $670 \mathrm{~km}$ depth. The transition zone gradients are inconsistent with adiabatic compression of a homogeneous mineral assemblage and a broad phase transition is implied. The depth and breadth of the inferred phase change is an important constraint on the mineralogy in this region. 

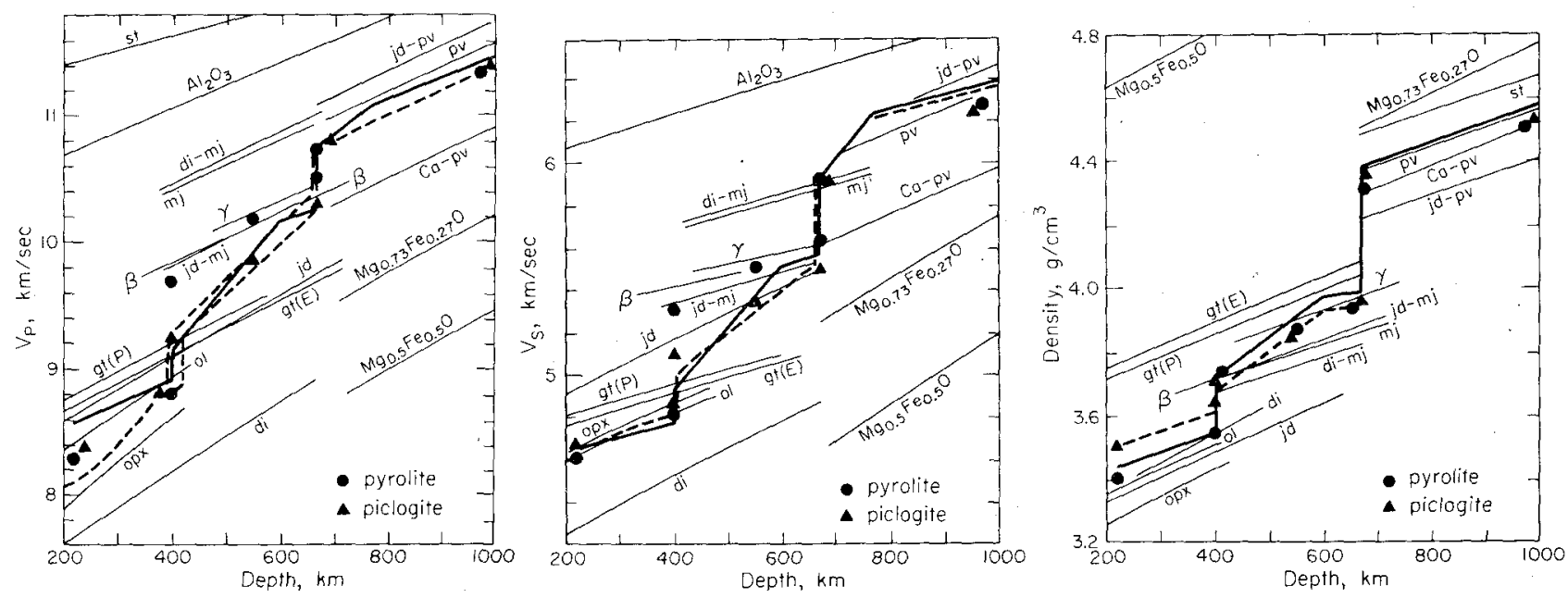

Fig. 1: $V_{p}, V_{s}$ and density for various minerals. Earth model PREM is shown (heavy solid line) along with a range of velocities from other studies (dashed lines). The dashed density profile is a perturbation of PREM which has the same mean upper mantle + transition zone density. Adiabats are initiated at $1400^{\circ} \mathrm{C}(\mathrm{P}=\mathrm{O})$. Circles and triangles indicate the properties of pyrolite and piclogite, respectively. The seismic profiles are substantially lower than pyrolite velocities (predominately $\beta$ or $\gamma,+$ mj) between $400-670 \mathrm{~km}$, but are well matched by piclogite. Velocity jumps for pyrolite do not satisfy the $400 \mathrm{~km}$ discontinuity. (ol, olivine; opx, orthopyroxene; di, diopside; jd, jadeite; gt(E, P), garnet (eclogite, pyro-

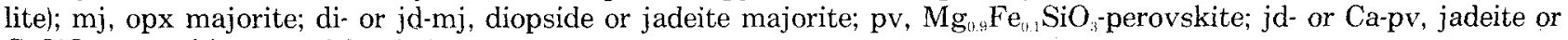
$\mathrm{CaSiO}_{3}$ perovskite; st, stishovite).

We compare two model mineral assemblages with the mantle data: one is pyrolite, which is predominately ol with minor opx $>\mathrm{gt} \sim \operatorname{cpx}$ (Ringwood, 1975), and the other is eclogitic, with gt $\approx$ omphacitic cpx $(\mathrm{jd}+\mathrm{di})>$ ol or opx. The pyrolite assemblage is $57 \%$ (by weight) ol, $17 \%$ opx, $14 \% \mathrm{gt}$ and $12 \% \mathrm{di}$. The proportions of the eclogite phases were adjusted to give a good fit of $\rho, V_{p}$ and $V_{s}$ with the seismic data between $220 \mathrm{~km}$ and $670 \mathrm{~km}$. Jadeite is an important component of mantle eclogite and serves to decrease the density and increase the velocity of the cpx-component of the mantle. A small amount of ol and opx is required to match the densities and velocities throughout the transition region, and phase changes in these components make it possible to satisfy the properties of the $400 \mathrm{~km}$ discontinuity as well. The overall chemistry of both assemblages does not change with depth but the phase chemistry, of course, does. The resulting eclogite composition has a low-pressure mineralogy of $23 \%$ di, $21 \% \mathrm{jd}, 37 \%$ gt, $16 \%$ ol and $3 \% \mathrm{opx}$, and is thus a picritic-eclogite, or "piclogite" in composition. The piclogite gt contains slightly more $\mathrm{Fe}^{2+}$ than the pyrolite gt, consistent with eclogite gt from kimberlites.

We have assumed that across the $400 \mathrm{~km}$ discontinuity all ol is converted to $\beta$, and opx is dissolved in the gt phase as $\mathrm{mj}$. At $550 \mathrm{~km}, 60 \%$ of the cpx has transformed to $\mathrm{mj}$, which coexists with $\gamma$ and opx-mj. At the bottom of the transition region all pyroxene is present as mj; below 670 $\mathrm{km} \gamma$ and gt-mj transform into pv-bearing assemblages. Although the phase relations for mineral compositions appropriate to our pyrolite and piclogite assemblages are not well determined, the above sequence of phase transformations is consistent with the results of Jeanloz and Thompson (1983), Akaogi and Akimoto (1979) and Liu (1980). An important point is that di and $j d$ are stable over a broader pressure range than opx. Phase changes in ol are very narrow relative to the width of the transition zone.

The results of our velocity (Voigt-Reuss-Hill averaging) and density calculations for piclogite and pyrolite are shown in Figure 1 and Table 1 . Between $200-400 \mathrm{~km}$ depth, both pyrolite and piclogite satisfy the mantle properties. The pyrolitic assemblage may be slightly preferred because $\mathrm{V}_{\mathrm{s}}$ of piclogite is about $2 \%$ high at a depth of $400 \mathrm{~km}$. However, the differences in velocity between pyrolite and piclogite are small from $200-400 \mathrm{~km}$ and we consider both models to fit the velocity data in this region.

Within the transition region (400-670 $\mathrm{km}$ depth), where we presume $\beta$ and $\gamma$ to be stable and the opx $\rightarrow$ mj reaction complete, the densities of both assemblages compare well with the density of the mantle. However, the velocities of pyrolite and piclogite are quite different. Pyrolite yields Svelocities 3-7\% higher and P-velocities 4-5\% higher than the seismic values. By contrast, $V_{p}$ and $V_{s}$ for piclogite provide a close match to the seismic velocity.

The variation of density with depth is poorly determined with available data but the average mantle density between 220 and $670 \mathrm{~km}$ is well constrained (Jordan and Anderson, 1974). The average densities of pyrolite and piclogite assemblages are both within $1 \%$ of PREM over this depth interval indicating that density does not provide a basis for distinguishing the two compositional models. Between 400 and $670 \mathrm{~km}$ depth pyrolite and piclogite are similar and slightly lower than PREM suggesting that PREM is too dense in this region. The dashed line in Fig. 1 shows a modification of PREM with the same average density between $220-670 \mathrm{~km}$.

Phase changes in pyrolite cannot explain the 400 and $670 \mathrm{~km}$ discontinuities (Table 1). It is traditional to refer to the $400 \mathrm{~km}$ discontinuity as the "olivine-spinel" phase change but the calculated velocity jumps in olivine are more than twice as high as observed. At $670 \mathrm{~km}$ the observed velocity increases by $5 \%$ and the boundary is sharp, rather than diffuse as predicted for an ol or opx phase change (Jeanloz and Thompson, 1983).

It is difficult to match the high velocity gradients observed between 400 and $670 \mathrm{~km}$ with a pyrolitic model. The transition zone gradients are much higher than is charac- 
Table 1. Compressional velocity, $V_{n}$, shear velocity, $V_{s}$, and density, $\rho$, for three mineral assemblages and the Earth's mantle. Velocity in $\mathrm{km} / \mathrm{sec} ; \rho$ in $\mathrm{g} / \mathrm{cm}^{3}$.

\begin{tabular}{|c|c|c|c|c|c|c|c|c|c|c|c|c|}
\hline \multirow{2}{*}{$\begin{array}{c}\text { Depth } \\
(\mathrm{km})\end{array}$} & \multicolumn{3}{|c|}{ Piclogite } & \multicolumn{3}{|c|}{ Pyrolite } & \multicolumn{3}{|c|}{$\begin{array}{c}\text { Perovskite } \\
\mathrm{Mg}_{0.4} \mathrm{Fe}_{0.1} \mathrm{SiO}_{3}\end{array}$} & \multicolumn{3}{|c|}{ Earth } \\
\hline & $\mathrm{V}_{\mathrm{p}}$ & $\mathrm{V}_{\mathrm{s}}$ & $\rho$ & $\mathrm{V}_{\mathrm{p}}$ & $\mathrm{V}_{4}$ & $\rho$ & $V_{p}$ & $V_{3}$ & $\rho$ & $V_{p}$ & $\mathrm{~V}_{\mathrm{s}}$ & $\rho$ \\
\hline 220 & 8.35 & 4.67 & 3.50 & 8.27 & 4.60 & 3.40 & & & & 8.35 & 4.64 & 3.44 \\
\hline $400-$ & 8.82 & 4.86 & 3.65 & 8.80 & 4.81 & 3.54 & & & & 8.82 & 4.77 & 3.54 \\
\hline $400+$ & 9.24 & 5.10 & 3.70 & 9.68 & 5.31 & 3.72 & & & & 9.24 & 5.00 & 3.72 \\
\hline 550 & 9.85 & 5.35 & 3.86 & 10.17 & 5.51 & 3.87 & & & & 9.90 & 5.37 & 3.91 \\
\hline $670-$ & 10.29 & 5.50 & 3.96 & 10.50 & 5.63 & 3.95 & & & & 10.26 & 5.56 & 3.99 \\
\hline $670+$ & 10.73 & 5.90 & 4.36 & 10.70 & 5.92 & 4.32 & 10.92 & 6.01 & 4.37 & 10.75 & 5.95 & 4.38 \\
\hline 971 & 11.35 & 6.25 & 4.53 & 11.32 & 6.27 & 4.50 & 11.51 & 6.33 & 4.55 & 11.42 & 6.38 & 4.56 \\
\hline
\end{tabular}

teristic of adiabatic compression of a homogeneous me dium. The $\gamma$ phase $\left(\mathrm{Fo}_{90}\right)$ is stable from about 475 to $670 \mathrm{~km}$ and with an ol-rich assemblage most of the transition region would be characterized by shallow velocity gradients. However, Akaogi and Akimoto (1979) show that dissolution of Ca-rich cpx into a gt-mj phase occurs over a pressure range that encompasses the transition zone. The stability field of gt-mj is also very broad for $\mathrm{Al}_{2} \mathrm{O}_{3}$-rich assemblages. Our calculations show that the gradual transformation of $\mathrm{CaO}$ - and $\mathrm{Al}_{2} \mathrm{O}_{3}$-rich cpx to mj can explain the high velocity gradients in the transition region. Thus, the available elasticity and phase stability data tend to favor a piclogitic mineral assemblage in the transition zone. Lees et al. (1983) were also unable to satisfy the seismic data for this region with an ol-opx assemblage.

In the lower mantle pyrolite, piclogite and $\left(\mathrm{Mg}_{0.9} \mathrm{Fe}_{0.1}\right) \mathrm{SiO}_{3}(\mathrm{pv})$ give comparable velocities and densities although the latter gives the best overall fit. The presence of a thermal boundary layer at $670 \mathrm{~km}$ would increase the temperature at the top of the lower mantle and this would favor the pure pv assemblage.

We conclude that piclogite $(44 \% \mathrm{cpx}, 37 \% \mathrm{gt}, 16 \% \mathrm{ol}$, $3 \% \mathrm{opx}$ ) is a more satisfactory candidate mineral assemblage than is pyrolite for the transition zone, even though pyrolite may not be outright rejected due to uncertainties in material properties. Jd is an important component of our piclogite and eclogite $\mathrm{cpx}$ from kimberlite pipes. Because pyrolite and piclogite have similar properties under shallow mantle and lower mantle conditions, neither model can be excluded for these regions, although a lower mantle assemblage closer to perovskite or pyrolite is cosmochemically more acceptable. Thus, either or both the 400 and $670 \mathrm{~km}$ discontinuities may be chemical boundaries. The seismic properties between $-200 \mathrm{~km}$ and $400 \mathrm{~km}$ are generally consistent with piclogite. If piclogite is adopted then the $400 \mathrm{~km}$ discontinuity would be due to phase changes in the ol and opx components of the assemblage and any chemical boundary between pyrolite and piclogite would be shallower.

At transition zone and lower mantle depths both piclogite and pyrolite have comparable densities. If the $670 \mathrm{~km}$ discontinuity is a chemical boundary, then there must be a density contrast of several percent to maintain the transition zone and lower mantle as chemically distinct regions. The persistence of a piclogite transition zone and a peridotite or pv lower mantle would require that the mj-gt to pv transition in piclogite occur at a substantially higher pressure than the $\gamma$-spinel to pv and/or mj-gt to pv transitions in a $\mathrm{Ca}$ - and $\mathrm{Al}$-poor pyrolitic assemblage. The work of Akaogi and Akimoto (1979), Jeanloz and Thompson
(1983) and Liu (1979) indicate that di-mj and $\mathrm{Al}_{2} \mathrm{O}_{3}$-rich gt may be stable to greater pressure than their $\mathrm{Mg}-\mathrm{Fe}$ and low- $\mathrm{Al}_{2} \mathrm{O}_{3}$ counterparts. More experimental work is required to clarify the effect of $\mathrm{Ca}, \mathrm{Na}$, and $\mathrm{Al}$ on these phase changes. The velocities and densities of piclogite and pyrolite are slightly less than the lower mantle values. If a thermal boundary layer exists at $670 \mathrm{~km}$ then temperatures may be in excess of those used here and a pv lower mantle would be favored, strengthening the arguments for a chemical discontinuity. A chemical boundary at $670 \mathrm{~km}$ would also help explain the sharpness of the $670 \mathrm{~km}$ discontinuity. Jd-pv, $\mathrm{CaSiO}_{3}$-pv and $\mathrm{Al}_{2} \mathrm{O}_{3}$-rich perovskites all appear to be less dense than $(\mathrm{Mg}, \mathrm{Fe}) \mathrm{SiO}_{3}$-perovskite and the mantle at $670+\mathrm{km}$. It is therefore unlikely that eclogite would sink into the lower mantle even if transformed to a perovskite bearing assemblage.

Acknowledgements. We thank D. Weidner and H. Sawamoto for preprints, and B. Hager, and T. Ahrens for helpful comments. This research was supported by NSF Grant No. EAR811-5236. Contribution No. 4000, Division of Geological and Planetary Sciences, California Institute of Technology, Pasadena, California 92115.

\section{References}

Anderson, Don L., The $650 \mathrm{~km}$ discontinuity, Geophys. Res. Lett., 3, 347-349, 1976.

Anderson, Don L., The upper mantle transition region: eclogite? Geophys. Res. Let., 6, 433-436, 1979.

Anderson, O. L., E. Schreiber, R. Leibermann, and N. Soga, Some elastic constant data on minerals relevant to geophysics, Rev. Geophys., 6, 491-524, 1968.

Akaogi, M. and S. Akimoto, High-pressure phase equilibria in a garnet Lherzolite, with special reference to $\mathrm{Mg}^{2+}-\mathrm{Fe}^{2+}$ partitioning among constituent minerals, Phys. Earth Planet. Int., 19, 31-51, 1979.

Dziewonski, A. and D. Anderson, Preliminary reference Earth model, Phys. Earth Planet. Int., 25, 297-356, 1981.

Given, J. and D. Helmberger, Upper mantle structure of northwestern Eurasia, J. Geophys., Res., 85, 7183$7194,1980$.

Grand, S. and D. Helmberger, Upper mantle shear structure of North America, Geophys. J. Roy. astron. Soc., in press, 1984.

Hughes, D. and T. Nishitake, Measurements of elastic wave velocity in armco iron and jadeite under high pressures and high temperatures, in Geophys. Papers Dedicated to Prof. Kenzo Sassa, Kyoto Univ., Kyoto, Japan, 1963. 
Jeanloz, R. and A. Thompson, Phase transitions and mantle discontinuities, Rev. Geophys. Space Phys., 21, 51$74,1983$.

Jordan, T. and Don L. Anderson, Earth structure from free oscillations and travel times, Geophys. J. Roy. astron. Soc., 36, 411-459, 1974.

Lees, A., S. Bukowinski and R. Jeanloz, Reflection properties of phase transition and compositional change models of the $670 \mathrm{~km}$ discontinuity, J. Geophys. Res., 88, 8145-8159, 1983.

Levien, L., D. Weidner and C. Prewitt, Elasticity of diopside, Phys. Chem. Minerals, 4, 105-113, 1979.

Liebermann, R., L. Jones and A. Ringwood, Elasticity of aluminate, titanate, stannate and germanate compounds with the perovskite structure, Phys. Earth Planet, Int., 14, 165-178, 1977.

Liu, L., Calculations of high-pressure phase transitions in the system $\mathrm{MgO}-\mathrm{SiO}_{2}$ and mantle discontinuities, Phys. Earth Planet. Int., 19, 319-330, 1979.

Liu, L., Phase relations in the system diopside-jadeite at high pressures and high temperatures, Earth Planet. Sci. Lett., 47, 3998-3402, 1980.

Reid, A. and A. Ringwood, High-pressure modification of $\mathrm{ScAlO}_{3}$ and some geophysical implications, J. Geophys. Res., 80, 3363-3370, 1975.
Ringwood, A., Composition and Petrology of the Earth's Mantle, McGraw-Hill, New York, 618 pp, 1975.

Ringwood, A. and A. Major, High-pressure transformations in pyroxenes, Earth Planet, Sci. Lett., 1, 351-357, 1966.

Ringwood, A. and A. Major, Synthesis of majorite and other high-pressure garnets and perovskites, Earth Planet. Sci. Lett., 12, 411-418, 1971.

Sammis, C., D. Anderson and T. Jordan, Application of isotropic finite strain theory to ultrasonic and seismological data, J. Geophys. Res., 75, 4478-4480, 1970.

Sawamoto, H., D. Weidner, S. Sasaki and M. Kumazawa, Single-crystal elastic properties of the modified spinel (beta) phase of $\mathrm{Mg}_{2} \mathrm{SiO}_{4}$, Science, in press, 1984.

Walck, M., The P-wave upper mantle structure beneath an active spreading center: the Gulf of California, Geophys. J. Roy. astr. Soc., in press, 1984.

Weidner, D., H. Sawamoto, S. Sasaki and M. Kumazawa, Single-crystal elastic properties of the spinel phase of $\mathrm{Mg}_{2} \mathrm{SiO}_{4}, J$. Geophys. Res., in press, 1984.

(Received December 15, 1983; accepted January 10, 1984.) 